\title{
Cutaneous Manifestations in POEMS Syndrome: Case Report and Review
}

\author{
Flauberto Sousa Marinho ${ }^{a}$ Rodrigo Pirmez ${ }^{a}$ Renata Nogueira ${ }^{b}$ \\ Tullia Cuzzi $^{\mathrm{c}}$ Celso Tavares Sodré ${ }^{\mathrm{a}}$ Marcia Silva $^{\mathrm{a}}$ \\ ${ }^{a}$ Sector of Dermatology and Post-Graduation Course, ${ }^{b}$ Sector of Neurology and \\ 'Sector of Pathology, University Hospital and School of Medicine, Federal University of \\ Rio de Janeiro, Rio de Janeiro, Brazil
}

\section{Key Words}

POEMS syndrome $\cdot$ Plasmocytoma $\cdot$ Polyneuropathy $\cdot$ Endocrinopathy $\cdot$ Monoclonal gammopathy · Skin changes

\begin{abstract}
The authors report a case of sensorimotor polyneuropathy, diffuse cutaneous hyperpigmentation, skin sclerodermiform thickening and papular lesions in the infraclavicular and abdominal region. Besides weight loss, there were diabetes mellitus and hypothyroidism. The alterations were consistent with POEMS (Polyneuropathy, Organomegaly, Endocrinopathy,

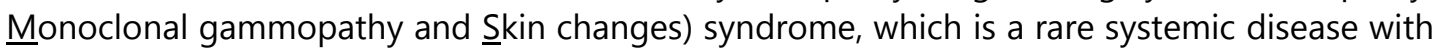
monoclonal proliferation of plasmacytes and slow progression. Cutaneous alterations are present in $68 \%$ of patients with diffuse cutaneous hyperpigmentation, plethora and acrocyanosis. Leukonychia, necrotizing vasculitis, hypertrichosis and cutaneous thickening of sclerodermiform type are also cited. The onset of multiple cutaneous angiomas in this syndrome has been observed in $24-44 \%$ of patients.

(c) 2015 S. Karger AG, Basel
\end{abstract}

\section{Introduction}

The first report about what is known as POEMS syndrome dates from 1938, when Scheinker observed the case of a 39-year-old man with plasmocytoma, sensorimotor polyneuropathy and cutaneous hyperpigmentation [1]. In 1956, Crow [2] reported two patients with osteosclerotic plasmocytoma, peripheral neuropathy, cutaneous pigmentation, leukonychia, lymphadenopathy and edema of the ankles, later designated as Crow-Fukase syndrome. In 1980, Bardwick et al. [3] created the acronym POEMS to represent a syndrome 
Marinho et al.: Cutaneous Manifestations in POEMS Syndrome: Case Report and Review

characterized by Polyneuropathy, 마ganomegaly, Endocrinopathy, Monoclonal gammopathy

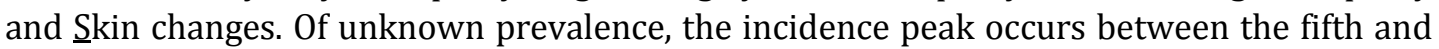
sixth decades of life. At first it was believed to be more common in Japanese progeny, but with growing knowledge of the entity it was also observed in European, African, Hispanic and Asian descendants [4]. Cutaneous alterations were found in about $65 \%$ of patients. The most common findings are hyperpigmentation, hypertrichosis, acrocyanosis, plethora and hemangiomas [5].

\section{Case Report}

The authors observed a 66-year-old woman with a previous history of paresthesia of distal prevalence in the upper limbs and the lower right limb associated with pain in the palmar and plantar region, with onset 1 year before, followed by reduction in strength, mainly in hands and feet, of slow and progressive evolution. During this period the patient noted diffuse skin darkening and appearance of papular lesions on the cervical and right infraclavicular region, abdomen and dorsum. She suffered a $20-\mathrm{kg}$ weight loss during evolution of the picture, besides diabetes mellitus and hypothyroidism. Examination showed diffuse cutaneous hyperpigmentation, atrophy of the interosseous muscles (fig. 1, fig. 2), sclerodermiform cutaneous thickening and normochromic, papular lesions (fig. 3) in the cervical region, abdominal and right infraclavicular region. At dermatoscopy of the infraclavicular lesions there was presence of red lakes (fig. 4). Neurological examination showed grade 3 strength of distal prevalence in the upper and lower limbs and hypopallesthesia in 'glove' and in 'boot'. These alterations were suggestive of sensorimotor polyneuropathy.

Ophthalmological examination did not reveal presence of papillary edema. Concerning laboratory examinations, thrombocytosis was noted, with rheumatoid factor $<10$; antinuclear factor, VDRL, anti-HIV, anti-HTLV and serology for hepatitis B and C were negative. Prolactin and cortisol dosages were within normal range. Electroneuromyography was compatible with polyneuropathy with predominance of demyelination and axonal degeneration. Bone marrow aspirate presented medullary plasmacytosis (9\% plasmacytes). Serous protein electrophoresis demonstrated a monoclonal peak in the gamma fraction and in immunofixation examination: monoclonal IgG/lambda peak.

Skeleton radiography revealed a lithic lesion with sclerotic borders in the left femur (fig. 5); histopathologic examination confirmed it to be a plasmocytoma. Histopathologic examination of the right infraclavicular lesion showed an exophytic lesion containing dispersed vascular connective structures (fig. 6), and increased magnification showed both thick- and thin-walled vascular structures, compatible with arteriovenous hemangioma (fig. 7). The lesion on the dorsum presented histopathologic characteristics of hemangioma in tufts and the lesion on the abdomen cherry hemangioma.

The patient was treated with radiotherapy of the femur due to the osteosclerotic lesions and showed improvement of the neurological picture as well as of hyperpigmentation and weigh loss.

\section{Discussion}

POEMS syndrome results from a rare proliferative monoclonal disease of systemic plasmacyte attack with indolent course [5]. The increased production of cytokines, such as interleukin-1 $\beta$ (IL-1 $\beta$ ), IL- 6 and tumor necrosis factor $\alpha$ (TNF- $\alpha$ ), besides vascular endo- 
Marinho et al.: Cutaneous Manifestations in POEMS Syndrome: Case Report and Review

thelial growth factor (VEGF), seems to play a relevant role in the pathogenesis of the disease [6-8].

TNF- $\alpha$ is related to peripheral neuropathy with demyelination, hepatomegaly, splenomegaly, endocrine dysfunctions (hypocortisolism, hypothyroidism and hyperprolactinemia), edema, weight loss and cutaneous manifestations with hypertrichosis and digital clubbing. IL- $1 \beta$ is correlated with cachexia, anorexia, cutaneous pigmentation caused by activation of the pro-opiomelanocortin gene, glucose intolerance, acceleration of the atherogenesis process and behavioral and psychiatric alterations. High levels of IL- 6 are involved in plasmacyte proliferation, monoclonal gammopathy, thrombocytosis, Castleman's disease, hemangiomas and microangiopathic glomerulopathy [6].

IL- 6 can be a useful marker for evaluation of disease progress, since increased serous levels of this cytokine were observed in patients with active disease and before each exacerbation of the clinical symptoms [7]. VEGF, detected in the platelets but with reported production by plasmacytes, induces increased vascular permeability and is a growth factor for endothelial cells with a relevant role in angiogenesis. VEGF is implicated in the development of ascites, pleural effusion, edema and organomegaly, besides neuropathy [8].

Presence of all related manifestations is not mandatory for the diagnosis of the disease, and no single laboratory evidence can be considered as pathognomonic. Dispenzieri et al. [9] in 2003 proposed a criteria system for the diagnosis of POEMS syndrome based on the frequency and relevance of the clinical and laboratory findings. They divided them into major, minor, known and possible associations. The major associations include polyneuropathy and monoclonal plasmaproliferative alterations. The minor associations are sclerotic bone lesions, Castleman's disease, organomegaly (hepatomegaly, splenomegaly, lymphadenopathy), edema, ascites, pleural effusion, endocrinopathy (adrenal, thyroid, hypophyseal, gonadal, parathyroid, pancreatic), skin disorders (hyperpigmentation, hypertrichosis, plethora, cutaneous hemangiomas, leukonychia) and papillary edema. The known associations are digital clubbing, weight loss, thrombocytosis, polycythemia and hyperhidrosis. At last, primary pulmonary arterial hypertension, obstructive pulmonary disease, thromboses, arthralgias, cardiomyopathy, fever, diarrhea and B12 hypovitaminosis are stated as possible associations. Establishing the diagnosis of POEMS syndrome requires the presence of two major criteria and at least one minor criterion $[4,5,9]$.

All patients present peripheral neuropathy with symptoms beginning in the feet with paresthesia and a sensation of 'coldness'. Motor involvement follows the sensitive picture. Both are of distal prevalence, symmetrical and progress with gradual proximal propagation, although rapid progression can also occur. Severe muscle weakness occurs in over half of patients, culminating with impairment to climb stairs, stand up from a chair or hold objects with the hands. Some patients report intense pain [4]. Electroneuromyography demonstrates a pattern of both demyelination and axonal degeneration [10]. About $50 \%$ of patients present organomegaly, which may manifest through hepatomegaly, splenomegaly or lymphadenopathy [11]. In some cases the adenopathy may be associated with Castleman's disease [12]. The most common endocrine abnormalities include hypogonadism, hypothyroidism, diabetes mellitus, adrenal insufficiency and hypoparathyroidism present in $67 \%$ of patients. Hypogonadism was the most common manifestation [9]. Due to the high incidence of diabetes and hypothyroidism in the general population, caution must be exercised before attributing those alterations to POEMS syndrome in case they appear isolated [5].

By definition, all patients present monoclonal plasmaproliferative disorder. Protein electrophoresis may not detect protein $M$ in half to one third of cases, which requires performance of serous or urinary immunofixation; almost always the light chain is of the lambda type, with prevalence of the IgA type $[4,11]$. Clonal plasmacyte proliferation can be dem- 
Marinho et al.: Cutaneous Manifestations in POEMS Syndrome: Case Report and Review

onstrated by sclerotic bone lesion biopsy. Bone marrow evaluation frequently only reveals a hypercellular pattern of the 'reactionary' type (only $15 \%$ of cases present significant medullary plasmacytosis) $[4,5]$.

Cutaneous disorders are present in $68 \%$ of patients, with diffuse cutaneous hyperpigmentation, plethora and acrocyanosis being the most common. Other manifestations include hyperhidrosis, leukonychia, necrotizing vasculitis, hypertrichosis and calciphylaxis. Cutaneous thickening of sclerodermiform type is also reported. These facts may be related to a greater collagen deposition by the dermal fibroblasts caused by increased VEGF levels $[9,13$, 14]. Hyperpigmentation can be diffuse or localized, occurring mainly on the extensor surfaces, dorsum, neck and armpits. It usually regresses in response to treatment. Leukonychia is quite a rare manifestation.

Occurrence of multiple cutaneous angiomas in POEMS syndrome was considered rare, but has been documented in $24-44 \%$ of patients. They appear during the course of the disease with firm papular lesions, with erythematous or violet coloration, on the trunk and in the proximal region of the limbs. They usually present variable histological characteristics, the most common being cherry hemangioma, lobular capillary hemangioma and, with less frequency, glomerular hemangioma. Some authors postulate a theory that the spectrum of the angiomatous lesions in POEMS syndrome might present the following behavior: the onset begins with a unidentified angiomatous lesion with a specific hemangioma, which later develops into an hemangioma in tufts, and later on evolves to a glomerular or other type of hemangioma [15]. Therefore, there would exist different stages of development or different endothelial proliferation grades in response to the angiogenic stimuli. Histopathology of glomerular hemangioma shows a capillary entanglement occupying a large vascular space in the dermis filled with endothelial cells, with an aspect resembling a renal glomerulus [16]. It is present in only $3 \%$ of cases and can precede the remaining signs and symptoms of the syndrome, allowing an early diagnosis [13]. It is not always associated with POEMS syndrome $[17,18]$.

Bone lesions are present in most of the individuals and are usually painless. They may be of the sclerotic, lithic (less frequent) or mixed (lithic with sclerotic borders) type. There is a preference for involvement of the spine, pelvis bones, ribs and proximal portion of the extremities [5, 19].

The average survival is around 13.7 years in large series analysis. Therapeutic options include: radiotherapy, indicated in cases of simple or multiple sclerotic lesions of limited location; chemotherapy (melphalan and prednisone, capable to produce an objective response in $90 \%$ of cases; cyclophosphamide or polychemotherapy); and autologous bone marrow transplantation, which can be used in young patients with disseminated osteosclerotic disease [5, 20, 21]. Monoclonal blocking antibodies for the VEGF receptor (bevacizumab) were employed successfully according to some reports [5, 22].

\section{Conclusion}

Our patient had two major criteria (sensorimotor polyneuropathy and monoclonal plasmaproliferative disorder) and three minor criteria (sclerotic bone lesion; endocrine disorders - diabetes mellitus and hypothyroidism; cutaneous manifestations - hyperpigmentation, cutaneous thickening with sclerodermiform pattern and cutaneous hemangiomas). Additionally, thrombocytosis and weight loss are known to be associated with this syndrome. The patient was forwarded to the hematology service for performance of specific therapy and continues neurological follow-up for neuropathy. 


\section{Case Reports in Dermatology}

\begin{tabular}{l|l}
\hline \multicolumn{2}{l}{ Case Rep Dermatol 2015;7:61-69 } \\
\hline DOI: $10.1159 / 000381302$ & $\begin{array}{l}\text { C } 2015 \text { S. Karger AG, Basel } \\
\text { www.karger.com/cde }\end{array}$ \\
\hline
\end{tabular}

Marinho et al.: Cutaneous Manifestations in POEMS Syndrome: Case Report and Review

\section{Disclosure Statement}

The authors have no conflict of interest for this publication.

\section{References}

1 Livingston J, Cobiella C, Hall-Craggs MA: POEMS syndrome - a unique presentation of a rare paraneoplastic syndrome. BMJ Case Rep DOI: 10.1136/bcr.09.2010.3324.

$\longrightarrow 2$ Crow RS: Peripheral neuritis in myelomatosis. Br Med J 1956;2:802-804.

-3 Bardwick PA, Zvaifler NJ, Gill GN, Newman D, Greenway GD, Resnick DL: Plasma cell dyscrasia with polyneuropathy, organomegaly, endocrinopathy, M protein, and skin changes: the POEMS syndrome. Report on two cases and a review of the literature. Medicine (Baltimore) 1980;59:311-322.

4 Dispenzieri A, Gertz MA: POEMS syndrome. Orphanet encyclopedia 2005. http://www.orpha.net/data/ patho/GB/uk-POEMS.pdf (accessed December 4, 2014).

5 Pinto Neto JV: Síndrome de POEMS (mieloma osteoesclerótico). Rev Bras Hematol Hemoter 2007;29: 98-102.

6 Gherardi RK, Bélec L, Soubrier M, Malapert D, Zuber M, Viard JP, Intrator L, Degos JD, Authier FJ: Overproduction of proinflammatory cytokines imbalanced by their antagonists in POEMS syndrome. Blood 1996;87:1458-1465.

7 Hitoshi S, Suzuki K, Sakuta M: Elevated serum interleukin-6 in POEMS syndrome reflects the activity of the disease. Intern Med 1994;33:583-587.

-8 Matsui H, Udaka F, Kubori T, Oda M, Nishinaka K, Kameyama M: POEMS syndrome demonstrating VEGF decrease by ticlopidine. Intern Med 2004;43:1082-1083.

-9 Dispenzieri A, Kyle RA, Lacy MQ, Rajkumar SV, Therneau TM, Larson DR, Greipp PR, Witzig TE, Basu R, Suarez GA, Fonseca R, Lust JA, Gertz MA: POEMS syndrome: definitions and long-term outcome. Blood 2003;101:2496-2506.

10 Horta P, Quevedo I: Síndrome de POEMS: caso clínico. Rev Med Chil 2004;132:485-488.

11 Oehadian A, Prasetya D, Fadjari TH: POEMS syndrome: a rare case of monoclonal plasmaproliferative disorder. Acta Med Indones 2010;42:100-103.

12 Gherardi RK, Bélec L, Fromont G, Divine M, Malapert D, Gaulard P, Degos JD: Elevated levels of interleukin-1 beta (IL-1 beta) and IL- 6 in serum and increased production of IL-1 beta mRNA in lymph nodes of patients with polyneuropathy, organomegaly, endocrinopathy, M protein, and skin changes (POEMS) syndrome. Blood 1994;83:2587-2593.

$\checkmark 13$ Jeunon T, Sampaio AL, Caminha RC, Reis CU, Dib C: Hemangioma glomerulóide e a síndrome POEMS. Relato de dois casos e revisão da literatura. An Bras Dermatol 2011;86:1167-1173.

14 Barete S, Mouawad R, Choquet S, Viala K, Leblond V, Musset L, Amoura Z, Khayat D, Francès C: Skin manifestations and vascular endothelial growth factor levels in POEMS syndrome. Arch Dermatol 2010;146: 615-623.

15 Tsai C, Lai C, Chan H, Kuo T: Glomeruloid hemangioma: a specific cutaneous marker of POEMS syndrome. Int J Dermatol 2001;40:403-405.

16 Kingdon EJ, Phillips BB, Jarmulowicz M, Powis SH, Vanderpump MP: Glomeruloid haemangioma and POEMS syndrome. Nephrol Dial Transplant 2001;16:2105-2107.

17 González-Guerra E, Haro MR, Farina MC, Martin L, Manzarbeitia L, Requena L: Glomeruloid haemangioma is not always associated with POEMS syndrome. Clin Exp Dermatol 2009;34:800-803.

18 Yuri T, Yamazaki F, Takasu K, Shikata N, Tsubura A: Glomeruloid hemangioma. Pathol Int 2008;58:390-395.

19 Lopes Neto LC, Chiarantano RS, Bordalo-Rodrigues MB: Which is your diagnosis? Radiol Bras 2008;41:7-8.

20 Rathore NK, Sharma A, Sathpathy SP, Walke R: Oncological progression of bone plasmocytoma to POEMS syndrome. J Cancer Res Ther 2011;7:366-367.

21 Kuwabara S, Hattori T, Shimoe Y, Kamitsukasa I: Long term melphalan-prednisolone chemotherapy for POEMS syndrome. J Neurol Neurosurg Psychiatry 1997;63:385-387.

-22 Straume O, Bergheim J, Ernst P: Bevacizumab therapy for POEMS syndrome. Blood 2006;107:4972-4974. 
Marinho et al:: Cutaneous Manifestations in POEMS Syndrome: Case Report and Review

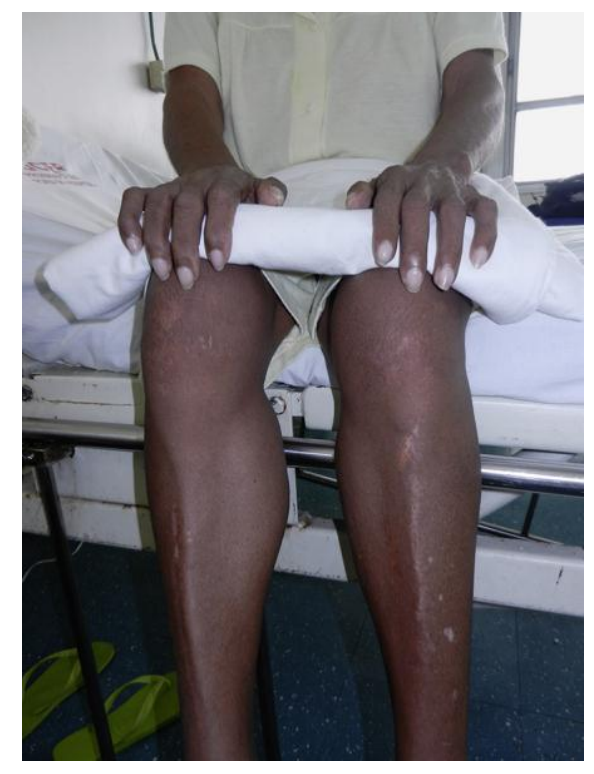

Fig. 1. Diffuse cutaneous hyperpigmentation and sclerodactyly on the legs and hands.

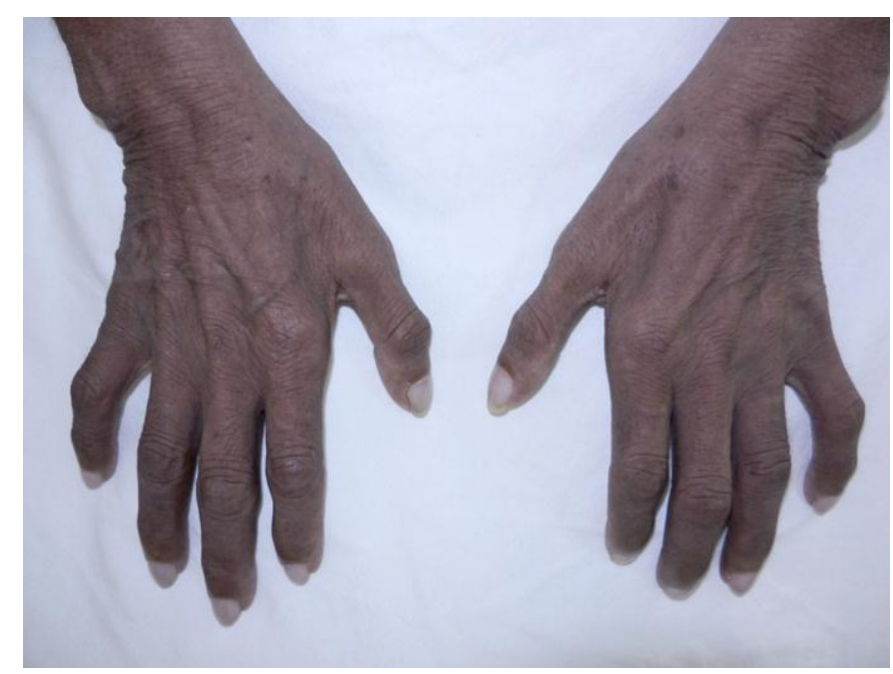

Fig. 2. Diffuse cutaneous hyperpigmentation, sclerodactyly and interosseous muscle atrophy on the hands. 
Marinho et al.: Cutaneous Manifestations in POEMS Syndrome: Case Report and Review

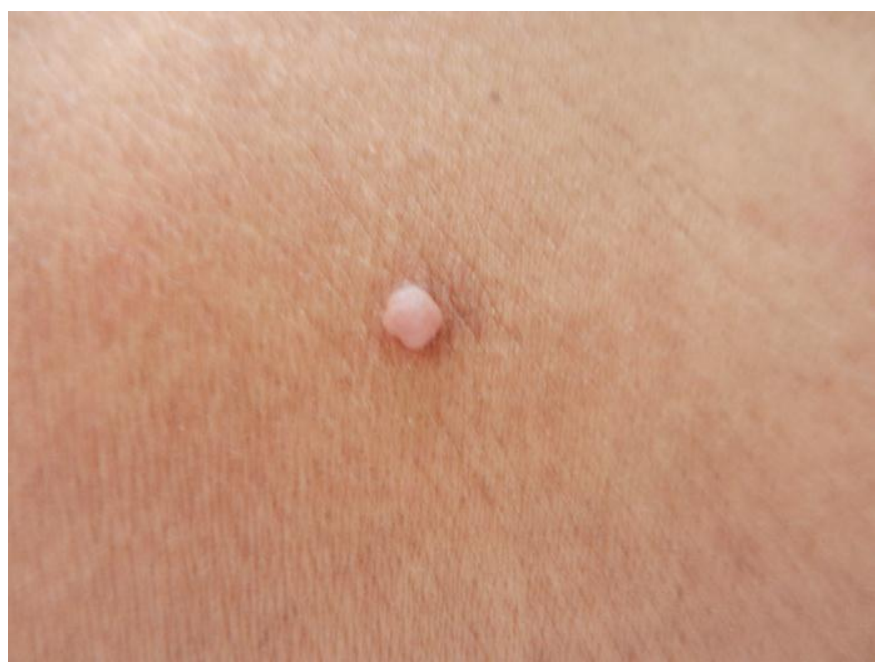

Fig. 3. Papular lesion in the right infraclavicular region.

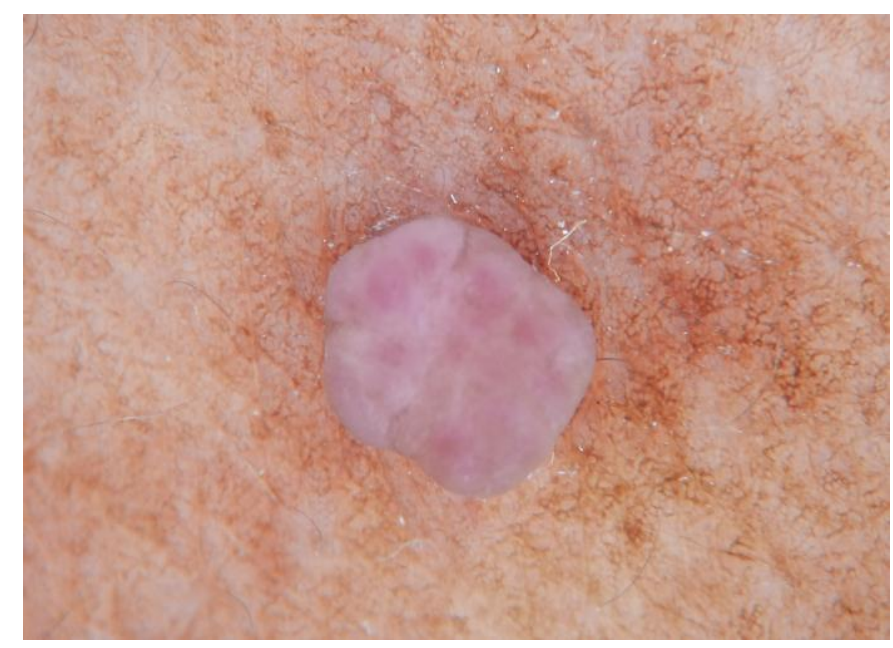

Fig. 4. Papular lesion with presence of red lakes. 


\section{Case Reports in Dermatology}

Case Rep Dermatol 2015;7:61-69

DOI: $10.1159 / 000381302$

(C) 2015 S. Karger AG, Basel www.karger.com/cde

Marinho et al.: Cutaneous Manifestations in POEMS Syndrome: Case Report and Review

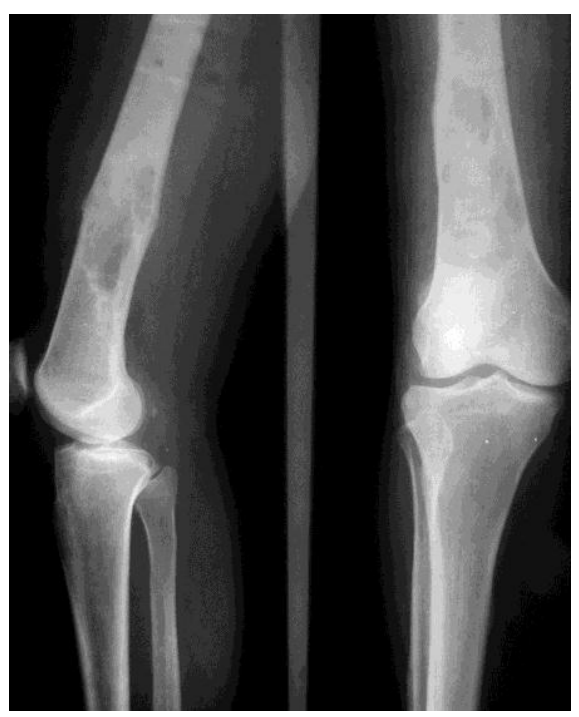

Fig. 5. Anteroposterior and profile X-ray of left thigh showing a lithic lesion with sclerotic borders in the left femur.

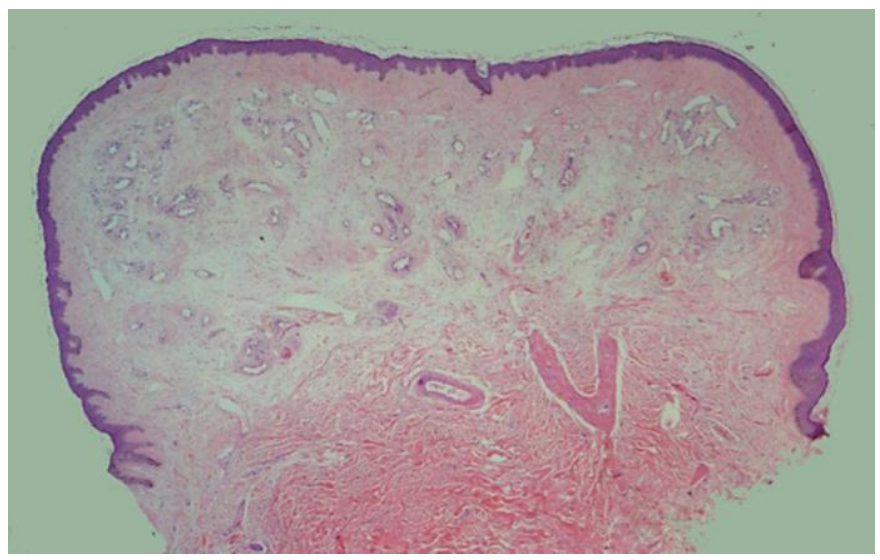

Fig. 6. Exophytic lesion containing vascular structures in dispersed connective stroma. 
Case Reports in
Dermatology

Case Rep Dermatol 2015;7:61-69

DOI: $10.1159 / 000381302$

(c) 2015 S. Karger AG, Basel www.karger.com/cde

Marinho et al.: Cutaneous Manifestations in POEMS Syndrome: Case Report and Review

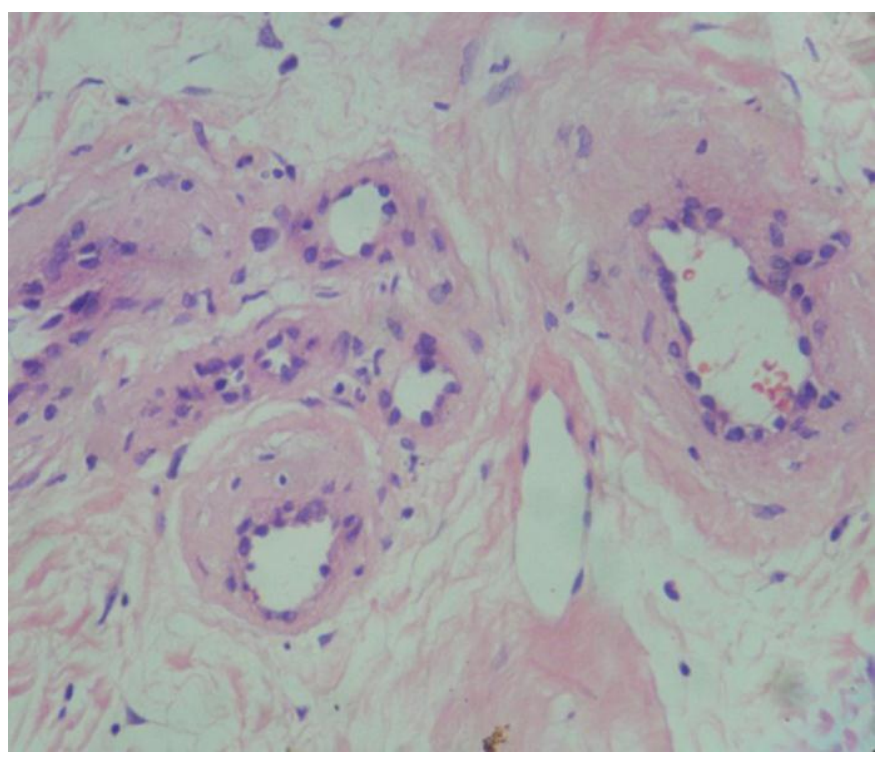

Fig. 7. Vascular structures with thick and thin walls. 


\section{Erratum}

In the article by Marinho et al. entitled 'Cutaneous manifestations in POEMS syndrome: case report and review' [Case Rep Dermatol 2015;7:61-69, DOI: $10.1159 / 000381302]$, the last name of the last-mentioned author is partly wrong. Rather than Silva it should read Ramos-e-Silva. 